\title{
THE CALCULATION OF VALUES OF EIGENFUNCTIONS OF THE PERTURBED SELF-ADJOINT OPERATORS BY REGULARIZED TRACES METHOD
}

\author{
S.N. Kakushkin ${ }^{1}$, kakushkin-sergei@mail.ru, \\ S.I. Kadchenko ${ }^{1}$, kadchenko@masu.ru. \\ ${ }^{1}$ Nosov Magnitogorsk State Technical University, Magnitogorsk, Russian \\ Federation.
}

The authors developed a numerical non-iterative method of finding of the value of eigenfunctions of perturbed self-adjoint operators, which was called the method of regularized traces. It allows to find the value of eigenfunctions of perturbed discrete operators, using the spectral characteristics of the unperturbed operator and the eigenvalues of the perturbed operator. In contrast to the known methods, in the method of regularized traces the value of eigenfunctions are found by the linear equations. It significantly increases the computational efficiency. The difficulty of the method is to find sums of functional series of "suspended" corrections of perturbation theory, which can be found only numerically. The formulas, which are convenient to find "suspended" corrections such that one can approximate the amount of these functional series by summing up of them, are presented in the paper. However, if a norm of the perturbing operator is large, then the summation of "suspended" corrections can be not effective. We obtain analytical formulas, which allow to find the values of sums of functional series of "suspended" corrections of perturbation theory in the discrete nodes without direct summation of its terms. Computational experiments are performed. These experiments allowed to find the values of the eigenfunctions of the perturbed one-dimensional Laplace operator. The experimental results showed the accuracy and computational efficiency of the developed method.

Keywords: method of regularized traces; perturbed operators; eigenvalues; eigenfunctions; multiple spectrum; "suspended" corrections of perturbation theory.

\section{Introduction}

The problem of finding of the eigenvalues and the eigenfunctions of the perturbed self-adjoint operators is important for both applied mathematics and other fields of basic research. In this regard, the establishment of new and development of existing numerical methods for solving of spectral problems generated by perturbation discrete operators, are an actual problems of modern mathematical modeling of different processes of nature.

A new method was developed in the works, which were written by S.I. Kadchenko, together with academician V.A. Sadovnichii and professor V.V. Dubrovskii. This method allows to calculate the first eigenvalues of perturbed self-adjoint operators and was called the method of regularized traces (RT). Later, S.I. Kadchenko got very simple formulas for calculating of eigenvalues of perturbation discrete operators and removed a number of strong restrictions on the unperturbed and perturbing operators [1]. It greatly increased the computational effectiveness and greatly expanded the class of operators to which the method can be applied. S.I. Kadchenko and S.N. Kakushkin developed the ideas of the method of regularized traces. As a result, a non-iterative method, which allows to find the values of eigenfunctions of perturbed discrete operators in discrete nodes of the domain of definition, was developed [2-4]. The main theorems, which are used in the construction 
of this method, are presented in this paper. Also formulas, which allow to calculate the values of sums of functional series of "suspended" corrections of perturbation theory of discrete operators, were obtained, and computational experiment was performed.

Let $T$ be a discrete lower semibounded operator, and $P$ be bounded operator, and both are set in a separable Hilbert space $H$ with domains of definition in $D$. Suppose that the eigenvalues $\left\{\lambda_{n}\right\}_{n=1}^{\infty}$ of operator $T$ are known and are numbered in decreasing order of their values. Also suppose that the orthonormal eigenfunctions $\left\{v_{n}(x)\right\}_{n=1}^{\infty}(x \in D)$, corresponding to these eigenvalues, are known and form a basis in $H$. Let $\nu_{n}$ be algebraic multiplicity of the eigenvalue $\lambda_{n}$. Denote a number of unequal to each other $\lambda_{n}$, lying inside the circle $T_{n_{0}}$, having radius $\rho_{n_{0}}=\frac{\left|\lambda_{n_{0}+1}+\lambda_{n_{0}}\right|}{2}$ and a centre at the origin of the complex plane, by $n_{0}$. Let $\left\{\mu_{n}\right\}_{n=1}^{\infty}$ be eigenvalues of the operator $T+P$, which are numbered in not decreasing order of their real parts, and $\left\{u_{n}(x)\right\}_{n=1}^{\infty}(x \in D)$ be corresponding eigenfunctions.

The following theorem was obtained in paper [5].

Theorem 1. Let $T$ be a discrete lower semibounded operator, and $P$ be bounded operator, and both are set in a separable Hilbert space $H$ with domains of definition in D. If the inequalities $q_{n}=\frac{2\|P\|}{\left|\lambda_{n+\nu_{n}}-\lambda_{n}\right|}<1$ are hold for all $n \in \mathbb{N}$, then $m_{0}=\sum_{n=1}^{n_{0}} \nu_{n}$ eigenfunctions of the operator $T+P$ are the solutions of system of nonlinear equations

$$
\sum_{j=1}^{m_{0}} \mu_{j}^{p} u_{j}(x) \bar{u}_{j}(y)=\sum_{j=1}^{m_{0}} \lambda_{j}^{p} v_{j}(x) \bar{v}_{j}(y)+\sum_{k=1}^{t} \alpha_{k}^{(p)}\left(m_{0}, x, y\right)+\varphi_{t}^{(p)}\left(m_{0}, x, y\right) .
$$

Here

$$
\alpha_{k}^{(p)}\left(m_{0}, x, y\right)=\frac{(-1)^{k}}{2 \pi i} \int_{T_{n_{0}}} \lambda^{p}\left[K_{T}\left(x, z_{k}, \lambda\right) \circ P_{z_{k}}\right]^{k} \circ K_{T}\left(z_{k}, y, \lambda\right) d \lambda
$$

are $k$-th corrections of perturbation theory to the "suspended" spectral function of the operator $T+P$ of integer order $p$;

$$
\begin{gathered}
\varphi_{t}^{(p)}\left(m_{0}, x, y\right)=\frac{(-1)^{t+1}}{2 \pi i} \int_{T_{n_{0}}} \lambda^{p}\left[K_{T}\left(x, z_{t+1}, \lambda\right) \circ P_{z_{t+1}}\right]^{t+1} \circ \\
\circ K_{T+P}\left(z_{t+1}, y, \lambda\right) d \lambda ;
\end{gathered}
$$

operation "o" is introduced by the rule

$$
(K \circ P \circ Q)(x, y, \lambda)=\int_{D} K(x, z, \lambda) P_{z} Q(z, y, \lambda) d z ;
$$

$K_{T}(x, y, \lambda)-$ kernel of the resolvent $R_{\lambda}(T)$ of operator $T ; T_{n_{0}}$ - circle having radius $\rho_{n_{0}}=$ $\frac{\left|\lambda_{n_{0}+1}+\lambda_{n_{0}}\right|}{2}$ and centre at the origin of the complex plane.

It can be shown (using, for example, [6, chapter V, $\S 4$, p. 331]), that $\left|\varphi_{t}^{(p)}\left(m_{0}, x, y\right)\right| \rightarrow$ 0 for $m_{0} \rightarrow \infty$. Then the system of equations (1) becomes:

$$
\sum_{j=1}^{m_{0}} \mu^{p} u_{j}(x) \bar{u}_{j}(y)=\sum_{j=1}^{m_{0}} \lambda^{p} v_{j}(x) \bar{v}_{j}(y)+\sum_{k=1}^{t} \alpha_{k}^{(p)}\left(m_{0}, x, y\right)+\varepsilon_{t}^{(p)}\left(m_{0}, x, y\right),
$$


where

$$
\varepsilon_{t}^{(p)}\left(m_{0}, x, y\right)=\sum_{k=t+1}^{\infty} \alpha_{k}^{(p)}\left(m_{0}, x, y\right) .
$$

The system of equations (3) is the basis of a new non-iterative numerical method of finding of the values of the eigenfunctions $u_{j}(x)$ of perturbed operator $T+P$ at the nodes of the sampling.

\section{The RT Method to Calculate the Values of Eigenfunctions of Perturbed Discrete Operators}

The difficulty of using of the system of equations (3) to calculate the values of products of $u_{j}(x) \bar{u}_{j}(y)$ is to find sums of "suspended" corrections of perturbation theory $\sum_{k=1}^{\infty} \alpha_{k}^{(p)}\left(m_{0}, x, y\right)$, which can be find only numerically. The estimates of "suspended" corrections of perturbation theory were obtained by analytical formulas.

Theorem 2. Let $T$ be a discrete lower semibounded operator, and $P$ be bounded operator, and both are set in a separable Hilbert space $H$. If the inequalities $q_{n}<1$ are hold for all $n \in \mathbb{N}$, then for "suspended" corrections of perturbation theory $\alpha_{m}^{(p)}\left(m_{0}, x, y\right)$ of operator $T+P$ the following estimates are true:

$$
\left|\alpha_{m}^{(p)}\left(m_{0}, x, y\right)\right| \leq \frac{C_{0}^{2}}{2 \pi}\|P\| \rho_{n_{0}}^{p+1} q_{n_{0}}^{m-1} S_{\lambda}
$$

Here $S_{\lambda}=\sup _{\lambda \in T_{n_{0}}}\left(\sum_{k=1}^{\infty} \frac{1}{\left|\lambda-\lambda_{k}\right|}\right)^{2},\left|v_{i}(x)\right| \leq C_{0}, \forall i=\overline{1, \infty}$.

The convergence of sums of Rayleigh - Schrodinger functional series $\sum_{m=1}^{\infty} \alpha_{m}^{(p)}\left(m_{0}, x, y\right)$ is proved in paper [7] using (4). There the estimates of them were obtained.

Theorem 3. Let $T$ be a discrete lower semibounded operator, and $P$ be bounded operator, and both are set in a separable Hilbert space $H$. If the inequalities $q_{n}<1$ are hold for all $n \in \mathbb{N}$, then for sum remainders of Rayleigh - Schrodinger functional series $\varepsilon_{t}^{(p)}\left(m_{0}, x, y\right)$ of operator $T+P$ for any $t, p, m_{0} \in \mathbb{N}$ the following estimates are true:

$$
\left|\varepsilon_{t}^{(p)}\left(m_{0}, x, y\right)\right| \leq \frac{C_{0}^{2}}{2 \pi}\|P\| \rho_{n_{0}}^{p+1} S_{\lambda} \frac{q_{n_{0}}^{t}}{1-q_{n_{0}}} .
$$

Here $S_{\lambda}=\sup _{\lambda \in T_{n_{0}}}\left(\sum_{k=1}^{\infty} \frac{1}{\left|\lambda-\lambda_{k}\right|}\right)^{2},\left|v_{i}(x)\right| \leq C_{0}, i=\overline{1, \infty}$.

If the norm of the perturbing operator $P$ is small, then it is enough to approach the sum of functional series $\sum_{k=1}^{\infty} \alpha_{k}^{(p)}\left(m_{0}, x, y\right)$ by the first "suspended" corrections. The limiting absolute errors of finding sums of functional series $\sum_{k=1}^{\infty} \alpha_{k}^{(p)}\left(m_{0}, x, y\right)$ are evaluated by the formulas (5). In the following theorem we obtain formulas for finding the "suspended" corrections of theory of perturbations $\alpha_{k}^{(p)}\left(m_{0}, x, y\right)$ of discrete operators, such that one can 
find approximately the sum of Rayleigh - Schrodinger functional series $\sum_{k=1}^{\infty} \alpha_{k}^{(p)}\left(m_{0}, x, y\right)$ by summing up them.

Theorem 4. Let $T$ be a discrete lower semibounded operator, $P$ be bounded operator, and both are set in a separable Hilbert space $H$. Suppose the inequalities $q_{n}<1$ are true for all $n \in \mathbb{N}$. Then the "suspended" corrections of theory of perturbations $\alpha_{k}^{(p)}\left(m_{0}, x, y\right)$ for any natural $k, p$ and $m_{0}$ can be find by the formulas:

$$
\begin{gathered}
\alpha_{k}^{(p)}\left(m_{0}, x, y\right)=-\sum_{n=1}^{m_{0}} \sum_{j_{1}, \ldots, j_{k+1}=1}^{\infty} v_{j_{1}}(x) \bar{v}_{j_{k+1}}(y) \times \\
\times r_{k}^{(p)}\left(n, j_{1}, \ldots, j_{k+1}\right) \prod_{m=1}^{k} V_{j_{m} j_{m+1}},
\end{gathered}
$$

where

$$
r_{k}^{(p)}\left(n, j_{1}, \ldots, j_{k+1}\right)=\left\{\begin{array}{l}
0, \forall j_{m} \neq n, m=\overline{1, k+1} \\
\frac{1}{k !} \lim _{\lambda \rightarrow \lambda_{n}} \frac{d^{k}}{d \lambda^{k}} \lambda^{p}, l=k+1 ; \\
\frac{1}{(l-1) !} \lim _{\lambda \rightarrow \lambda_{n}} \frac{d^{l-1}}{d \lambda^{l-1}}\left(\frac{\lambda^{p}}{\prod_{m=1}^{k-l+1}\left(\lambda-\lambda_{j_{m}}\right)}\right), 0<l \leq k
\end{array}\right.
$$

$V_{i, j}=\left(P v_{i}, v_{j}\right)$ - inner product; $l$ - number of coincidences $j_{m}=n, m=\overline{1, k+1}$.

The main determinant of the system of equations (1) is a Vandermonde determinant, and is different from zero. Therefore one can find its solution, with respect to products of $u_{j}(x) \bar{u}_{j}(y)$, by any appropriate method [5]. In the future, it is assumed that the eigenvalues $\mu_{n}$ are found by new RS method, which was obtained by S.I. Kadchenko in papers $[1,9]$.

The technique of finding the values of products of eigenfunctions $u_{j}(x) \bar{u}_{j}(y)$ of operators $T+P$ is presented in the following theorem. This technique uses linear formulas of calculation and allows do not direct solve a system of nonlinear equations (3).

Theorem 5. Let $T$ be a discrete lower semibounded operator, $P$ be bounded operator, and both are set in a separable Hilbert space $H$ with domain of definition D. Suppose the inequalities $q_{n}<1$ are true for all $n \in \mathbb{N}$. Then the value of the product of eigenfunction $u_{n}(x)$ and its conjugate one $\bar{u}_{n}(y)$ for all values of the arguments $x, y \in D$, can be find by the formulas:

$$
\begin{gathered}
u_{n}(x) \bar{u}_{n}(y)=\frac{1}{\mu_{n}}\left(\lambda_{n} v_{n}(x) \bar{v}_{n}(y)+\right. \\
\left.+\sum_{k=1}^{t}\left[\alpha_{k}^{(1)}(n, x, y)-\alpha_{k}^{(1)}(n-1, x, y)\right]\right)+\widetilde{\varepsilon}_{t}^{(1)}(n, x, y),
\end{gathered}
$$

where for $\widetilde{\varepsilon}_{t}^{(1)}(n, x, y)$ the estimates

$$
\left|\widetilde{\varepsilon}_{t}^{(1)}(n, x, y)\right| \leq \frac{C_{0}^{2}}{2 \pi \mu_{n}}\|P\| S_{\lambda} \rho_{n}^{2} \frac{q^{t}}{1-q}, \forall t \in \mathbb{N}, n=\overline{1, m_{0}} \text { aretrue. }
$$

Here $S_{\lambda}=\sup _{\lambda \in T_{n_{0}}}\left(\sum_{k=1}^{\infty} \frac{1}{\left|\lambda-\lambda_{k}\right|}\right)^{2},\left|v_{i}(x)\right| \leq C_{0} \forall i=\overline{1, \infty}, q=\max _{n \geq 1} q_{n}$. 
In general, the values of the eigenfunctions of a perturbed self-adjoint operator are complex. The product of eigenfunction $u_{j}(x)\left(j=\overline{1, m_{0}}\right)$ and its conjugate one $\bar{u}_{j}(x)$ at the same point $x \in D$ is the module of values of eigenfunction $u_{j}(x)$. Therefore, one can not to restore the value of eigenfunction $u_{j}(x)$ by one point using the equation (3). But if we consider the equation (3) for different points $x$ and $y$, then it is possible to construct an algorithm for calculating the values of eigenfunctions.

Let us illustrate this for the case where the eigenfunctions $\left\{u_{n}(x)\right\}_{n=1}^{m_{0}}$ of operator $T+P$ are functions of $k$ variables: $x=\left(x_{1}, x_{2}, \ldots, x_{k}\right)$. We introduce the difference grid for arguments $x_{1}, x_{2} \ldots x_{k}$ with steps $h_{1}, h_{2} \ldots h_{k}$ respectively. Denote the number of nodes of the arguments $x_{1}, x_{2} \ldots x_{k}$ by $m_{1}, m_{2} \ldots m_{k}$. Let us write the values $x \in D$ at the nodes of a sample in the form

$$
x_{j_{1} j_{2} \ldots j_{k}}=\left(x_{1_{j_{1}}}, x_{2_{j_{2}}}, \ldots, x_{k_{j_{k}}}\right), j_{l}=\overline{1, m_{l}}, l=\overline{1, k} .
$$

Denote the right side $(7)$ by $\varphi_{n}(x, y)$. Then in the sampling nodes they take the form

$$
u_{n}\left(x_{i_{1} i_{2} \ldots i_{k}}\right) \bar{u}_{n}\left(y_{j_{1} j_{2} \ldots j_{k}}\right)=\varphi_{n}\left(x_{i_{1} i_{2} \ldots i_{k}}, y_{j_{1} j_{2} \ldots j_{k}}\right),
$$

where $i_{l}, j_{l}=\overline{1, m_{l}}, l=\overline{1, k}$.

Fix $k-1$ coordinates of the sampling points and write the equation (9) for two node points with coordinates $x_{i_{1} i_{2} \ldots i_{k}}, x_{i_{1} i_{2} \ldots i_{k}}$ and $x_{i_{1} i_{2} \ldots i_{k}+1}, x_{i_{1} i_{2} \ldots i_{k}}$

$$
u_{n}\left(x_{i_{1} i_{2} \ldots i_{k}+1}\right) \bar{u}_{n}\left(x_{i_{1} i_{2} \ldots i_{k}}\right)=\varphi_{n}\left(x_{i_{1} i_{2} \ldots i_{k}+1}, x_{i_{1} i_{2} \ldots i_{k}}\right) .
$$

First step is to find up to the sign the values of real and imaginary parts of $u_{n}\left(x_{i_{1} i_{2} \ldots i_{k}+1}\right)$ in the following form:

$$
u_{n}\left(x_{i_{1} i_{2} \ldots i_{k}+1}\right)= \pm \frac{\varphi_{n}\left(x_{i_{1} i_{2} \ldots i_{k}+1} x_{i_{1} i_{2} \ldots i_{k}}\right)}{\sqrt{\varphi_{n}\left(x_{i_{1} i_{2} \ldots i_{k}}, x_{i_{1} i_{2} \ldots i_{k}}\right)}}, i_{k}=\overline{1, m_{k}-1} .
$$

Similarly, we find the value of the eigenfunction $u_{n}$ in the rest of the node points.

Let us determine the sign within the grid for each value $u_{n}\left(x_{i_{1} i_{2} \ldots i_{k}}\right)$, which was founded by the formulas (10).

Second step is to determine the sign of the founded values. To this end fix $k-2$ values of coordinates of grid points (in the description of the algorithm, to be specific, fix the first $k-2$ index) and consider the product of the form

$$
u_{n}\left(x_{i_{1} i_{2} \ldots i_{k-1}, i_{k}}\right) \bar{u}_{n}\left(x_{i_{1} i_{2} \ldots i_{k-1}, i_{k}+1}\right)
$$

and

$$
u_{n}\left(x_{i_{1} i_{2} \ldots, i_{k-1}, i_{k}}\right) \bar{u}_{n}\left(x_{i_{1} i_{2} \ldots, i_{k-1}+1, i_{k}}\right) .
$$

Obviously, if the real part of the product (11) is negative, then values of function $u_{n}$ have different signs in the points $x_{i_{1} i_{2} \ldots, i_{k-1}, i_{k}}$ and $x_{i_{1} i_{2} \ldots, i_{k-1}, i_{k}+1}$. Therefore, one can determine the change in the signs of values of eigenfunctions by looking at the values of the real part of the products at each node.

Introduce an auxiliary coefficient $\xi$, which is equal 1 or -1 . For all $i_{k}=1$ the value $\xi$ is set to be -1 . We consider a sign of the product (12) at each sampling node and multiplie a modules of values $u_{n}\left(x_{i_{1} i_{2} \ldots i_{k-1}+1, i_{k}}\right)$ by $\xi$. If the real part of the product (12) is negative, then the sign of the coefficient $\xi$ is reversed. 
We carry out the same operations for the product (12). To not change the already changed in the previous step signs of values $u_{n}\left(x_{i_{1} i_{2} \ldots i_{k-1}, i_{k}}\right)$ for $i_{k-1}=1$ set $\xi=1$.

After the end of the described operations, we consider the coordinates of the remaining node points, increasing the values of fixed index $i_{1}, i_{2}, \ldots i_{k-2}$ in turn by one.

RT method algorithm composed by the above-described scheme is presented in [8].

In the following theorem we obtain formulas that are convenient to find the sums of functional series of "suspended" corrections of perturbation theory $\sum_{n=1}^{\infty} \alpha_{n}^{(p)}\left(m_{0}, x, y\right)$.

Theorem 6. Let $T$ be a discrete lower semibounded operator, and $P$ be bounded operator, and both are set in a separable Hilbert space $H$ with domain of definition in $D$. If the functions $\left\{v_{n}(x)\right\}_{n=1}^{\infty}(x \in D)$ form an orthonormal basis in $H$, then the sums of functional series of "suspended" perturbation theory corrections are foond by the formulas

$$
\begin{gathered}
\sum_{n=1}^{\infty} \alpha_{n}^{(p)}\left(m_{0}, x, y\right)=\sum_{k=1}^{m_{0}}\left[\mu_{k}^{p} v_{m}(x) \bar{v}_{m}(y)-\lambda_{k}^{p} v_{k}(x) \bar{v}_{k}(y)-\right. \\
-\mu_{k}^{p} \sum_{j, i=1}^{m-1}\left\{\frac{\bar{V}_{i m} \overline{\breve{A}_{i j}^{(k)}}}{\overline{\operatorname{det} \breve{\mathbf{A}}^{(k)}}} v_{m}(x) \bar{v}_{j}(y)+\frac{V_{i m} \breve{A}_{i j}^{(k)}}{\operatorname{det} \breve{\mathbf{A}}^{(k)}} v_{j}(x) \bar{v}_{m}(y)\right\}+ \\
\left.+\mu_{k}^{p} \sum_{j_{1}, j_{2}, i_{1}, i_{2}=1}^{m-1} \frac{V_{i_{1} m} \bar{V}_{i_{2} m} \breve{A}_{i_{1} j_{1}}^{(k)} \overline{\breve{A}_{i_{2} j_{2}}^{(k)}}}{\operatorname{det} \breve{\mathbf{A}}^{(k)} \overline{\operatorname{det} \breve{\mathbf{A}}^{(k)}}} v_{j_{1}}(x) v_{j_{2}}(y)\right]+\delta_{m}^{(p)}\left(m_{0}, x, y\right) .
\end{gathered}
$$

Here

$$
\begin{gathered}
\left|\delta_{m}^{(p)}\left(m_{0}, x, y\right)\right| \leq \sum_{k=1}^{m_{0}}\left|\mu_{k}\right|^{p}\left[2|C| \cdot\left|\varepsilon_{k}^{(m)}\right| \sum_{j=1}^{m}\left|x_{j}^{(k)}\right|+\left|\varepsilon_{k}^{(m)}\right|^{2}\right], \\
x_{l}^{(k)}=\left\{\begin{array}{c}
-\frac{1}{\operatorname{det} \breve{A}^{(k)}} \sum_{i=1}^{m-1} V_{i m} \breve{A}_{i l}^{(k)}, l=\overline{1, m-1} ; \\
1, l=m .
\end{array}\right.
\end{gathered}
$$

$C=\max _{i=\overline{1, m}}\left|v_{i}(x)\right|,\left|\delta_{m}^{(p)}\left(m_{0}, x, y\right)\right| \stackrel{m \rightarrow \infty}{\longrightarrow} 0, \varepsilon_{k}^{(m)}=u_{k}(x)-u_{k}^{(m)}(x), u_{k}^{(m)}(x)-$ approximation of the eigenfunction $u_{k}(x), \breve{\mathbf{A}}^{(k)}=\left(a_{i j}\right)_{i, j=1}^{m}, m \in \mathbb{N}, a_{i j}=V_{i j}+\left(\lambda_{i}-\mu_{k}\right) \delta_{i j}, V_{i j}=\left(P v_{i}, v_{j}\right), \delta_{i j}$ - Kronecker symbol, $\breve{A}_{i j}^{(k)}$ - cofactors to the matrix entries $\breve{\mathbf{A}}^{(k)}$. The bar denotes complex conjugation.

Proof.

Let the system of eigenfunctions $\left\{v_{n}(x)\right\}_{n=1}^{\infty}$ of operator $T$ form an orthonormal basis in $H$. Then the eigenfunctions $u_{k}(x)$ of operator $T+P$ can be represented as

$$
u_{k}(x)=\sum_{i=1}^{\infty} c_{i}^{(k)} v_{i}(x)
$$

Let $\varepsilon_{k}^{(m)}=u_{k}(x)-u_{k}^{(m)}(x)$, where $u_{k}^{(m)}(x)-m$-th partial sum of functional series (14).

Transform entries of the matrix $\mathbf{A}_{\mathbf{m} \times \mathbf{m}}=\left(a_{i j}\right)_{i, j=1}^{m}$, where $a_{i j}=\left((T+P) v_{i}, v_{j}\right)$. By the equations $T v_{n}=\lambda_{n} v_{n}$ and orthonormal system of functions $\left\{v_{n}\right\}_{n=1}^{\infty}$ one can write the chain of equalities:

$$
a_{i j}=\left((T+P) v_{i}, v_{j}\right)=\left(T v_{i}, v_{j}\right)+\left(P v_{i}, v_{j}\right)=
$$




$$
=\left(\lambda_{i} v_{i}, v_{j}\right)+\left(P v_{i}, v_{j}\right)=\lambda_{i}\left(v_{i}, v_{j}\right)+\left(P v_{i}, v_{j}\right)=\lambda_{i} \delta_{i j}+V_{i j},
$$

где $\delta_{i j}=\left\{\begin{array}{l}1, i=j, \\ 0, i \neq j\end{array} \quad-\right.$ Kronecker delta, $i, j=\overline{1, m}, m \in \mathbb{N}$.

An eigenvector $\mathbf{X}_{k}^{(m)}=\left(x_{1}^{(k)}, x_{2}^{(k)}, \ldots, x_{m}^{(k)}\right)^{T}$ of matrix $\mathbf{A}_{\mathbf{m} \times \mathbf{m}} \quad(k=\overline{1, m})$, corresponding to an eigenvalue $\mu_{k}$, must satisfy the matrix equation:

$$
\left(\mathbf{A}_{\mathbf{m} \times \mathbf{m}}-\mu_{k} \mathbf{E}\right) \mathbf{X}_{k}^{(m)}=0
$$

или

$$
\left\{\begin{array}{l}
\left(a_{11}-\mu_{k}\right) x_{1}^{(k)}+a_{12} x_{2}^{(k)}+\ldots+a_{1 m} x_{m}^{(k)}=0 \\
a_{21} x_{1}^{(k)}+\left(a_{22}-\mu_{k}\right) x_{2}^{(k)}+\ldots+a_{2 m} x_{m}^{(k)}=0 \\
\ldots \\
a_{m 1} x_{1}^{(k)}+a_{m 2} x_{2}^{(k)}+\ldots+\left(a_{m m}-\mu_{k}\right) x_{m}^{(k)}=0 .
\end{array}\right.
$$

An eigenvector $\mathbf{X}_{k}^{(m)}$ is defined up to a factor. Therefore, let component $x_{m}^{(k)}$ of vector $\mathbf{X}_{k}^{(m)}$ be equal to unity. Discard the last of the equations of the system (15). Note that the remaining equations are linearly independent. The resulting system of equations can be presented in matrix form:

$$
\begin{gathered}
\breve{\mathbf{A}}^{(k)}\left(\begin{array}{c}
x_{1}^{(k)} \\
x_{2}^{(k)} \\
\ldots \\
x_{m-1}^{(k)}
\end{array}\right)=\mathbf{B} \sim \\
\sim\left(\begin{array}{cccc}
a_{11}-\mu_{k} & a_{12} & \ldots & a_{1, m-1} \\
a_{21} & a_{22}-\mu_{k} & \ldots & a_{2, m-1} \\
\ldots & & & \\
a_{m-1,1} & a_{m-1,2} & \ldots & a_{m-1, m-1}-\mu_{k}
\end{array}\right)\left(\begin{array}{c}
x_{1}^{(k)} \\
x_{2}^{(k)} \\
\ldots \\
x_{m-1}^{(k)}
\end{array}\right)=\left(\begin{array}{c}
-a_{1 m} \\
-a_{2 m} \\
\ldots \\
-a_{m-1, m}
\end{array}\right) .
\end{gathered}
$$

From the form of a matrix $\mathbf{A}_{\mathbf{m} \times \mathbf{m}}-\mu_{k} \mathbf{E}$ it is followed that $a_{i m}=V_{i m}, i=\overline{1, m-1}$.

We solve heterogeneous system of equations (16) by the inverse matrix method:

$$
\begin{aligned}
& \left(\begin{array}{c}
x_{1}^{(k)} \\
x_{2}^{(k)} \\
\cdots \\
x_{m-1}^{(k)}
\end{array}\right)=\left[\breve{\mathbf{A}}^{(k)}\right]^{-1} \mathbf{B}= \\
& =\frac{1}{\operatorname{det} \breve{\mathbf{A}}^{(k)}}\left(\begin{array}{cccc}
\breve{A}_{11}^{(k)} & \breve{A}_{21}^{(k)} & \ldots & \breve{A}_{m-1,1}^{(k)} \\
\breve{A}_{12}^{(k)} & \breve{A}_{22}^{(k)} & \ldots & \breve{A}_{m-1,2}^{(k)} \\
\ldots & & & \\
\breve{A}_{1, m-1}^{(k)} & \breve{A}_{2, m-1}^{(k)} & \ldots & \breve{A}_{m-1, m-1}^{(k)}
\end{array}\right)\left(\begin{array}{c}
-V_{1 m} \\
-V_{2 m} \\
\ldots \\
-V_{m-1, m}
\end{array}\right)= \\
& =\frac{1}{\operatorname{det} \breve{\mathbf{A}}^{(k)}}\left(\begin{array}{c}
-\sum_{i=1}^{m-1} V_{i m} \breve{A}_{i 1}^{(k)} \\
-\sum_{i=1}^{m-1} V_{i m} \breve{A}_{i 2}^{(k)} \\
\ldots \\
-\sum_{i=1}^{m-1} V_{i m} \breve{A}_{i, m-1}^{(k)}
\end{array}\right) .
\end{aligned}
$$


Here $\breve{A}_{i j}^{(k)}$ - algebraic complements of entries of the matrix $\breve{\mathbf{A}}^{(k)}(i, j=\overline{1, m-1})$.

Therefore, components of the vector $\mathbf{X}_{k}^{(m)}(k=\overline{1, m})$ take the form

$$
x_{l}^{(k)}=\left\{\begin{array}{c}
-\frac{1}{\operatorname{det} \breve{\mathbf{A}}^{(k)}} \sum_{i=1}^{m-1} V_{i m} \breve{A}_{i l}^{(k)}, l=\overline{1, m-1} \\
1, l=m .
\end{array}\right.
$$

Solve a system of equations $(3)$ on $\sum_{k=1}^{\infty} \alpha_{k}^{(p)}\left(m_{0}, x, y\right)$ :

$$
\begin{gathered}
\sum_{k=1}^{\infty} \alpha_{k}^{(p)}\left(m_{0}, x, y\right)=\sum_{k=1}^{m_{0}}\left[\mu_{k}^{p} u_{k}(x) \bar{u}_{k}(y)-\lambda_{k}^{p} v_{k}(x) \bar{v}_{k}(y)\right]= \\
=\sum_{k=1}^{m_{0}}\left[\mu_{k}^{p}\left(u_{k}^{(m)}(x)+\varepsilon_{k}^{(m)}\right)\left(\bar{u}_{k}^{(m)}(y)+\bar{\varepsilon}_{k}^{(m)}\right)-\lambda_{k}^{p} v_{k}(x) \bar{v}_{k}(y)\right]= \\
=\sum_{k=1}^{m_{0}}\left\{\mu_{k}^{p}\left[u_{k}^{(m)}(x) \bar{u}_{k}^{(m)}(y)+\bar{\varepsilon}_{k}^{(m)} u_{k}^{(m)}(x)+\varepsilon_{k}^{(m)} \bar{u}_{k}^{(m)}(y)+\varepsilon_{k}^{(m)} \bar{\varepsilon}_{k}^{(m)}\right]-\lambda_{k}^{p} v_{k}(x) \bar{v}_{k}(y)\right\}= \\
=\sum_{k=1}^{m_{0}}\left[\mu_{k}^{p} u_{k}^{(m)}(x) \bar{u}_{k}^{(m)}(y)-\lambda_{k}^{p} v_{k}(x) \bar{v}_{k}(y)\right]+\sum_{k=1}^{m_{0}} \mu_{k}^{p}\left[\bar{\varepsilon}_{k}^{(m)} u_{k}^{(m)}(x)+\varepsilon_{k}^{(m)} \bar{u}_{k}^{(m)}(y)+\varepsilon_{k}^{(m)} \bar{\varepsilon}_{k}^{(m)}\right]= \\
=\sum_{k=1}^{m_{0}}\left[\mu_{k}^{p} u_{k}^{(m)}(x) \bar{u}_{k}^{(m)}(y)-\lambda_{k}^{p} v_{k}(x) \bar{v}_{k}(y)\right]+\delta_{m}^{(p)}\left(m_{0}, x, y\right) .
\end{gathered}
$$

Decompose the components of the eigenvector $\mathbf{X}_{k}^{(m)}$ on the elements of an orthonormal basis $\left\{v_{i}(x)\right\}_{i=1}^{m}(x \in D)$, using formulas (17):

$$
u_{k}^{(m)}(x)=\sum_{j=1}^{m} x_{j}^{(k)} v_{j}(x)=v_{m}(x)-\frac{1}{\operatorname{det} \breve{\mathbf{A}}^{(k)}} \sum_{j=1}^{m-1} \sum_{i=1}^{m-1} V_{i m} \breve{A}_{i j}^{(k)} v_{j}(x) .
$$

Substitute formulas (18) in term for $\sum_{k=1}^{\infty} \alpha_{k}^{(p)}\left(m_{0}, x, y\right)$ :

$$
\begin{aligned}
& \sum_{k=1}^{\infty} \alpha_{k}^{(p)}\left(m_{0}, x, y\right)=\sum_{k=1}^{m_{0}}\left[\mu_{k}^{p}\left(v_{m}(x)-\frac{1}{\operatorname{det} \breve{\mathbf{A}}^{(k)}} \sum_{j, i=1}^{m-1} V_{i m} \breve{A}_{i j}^{(k)} v_{j}(x)\right) \times\right. \\
& \left.\times\left(\bar{v}_{m}(y)-\frac{1}{\overline{\operatorname{det} \breve{\mathbf{A}}^{(k)}}} \sum_{j, i=1}^{m-1} \bar{V}_{i m}{\overline{\breve{A}_{i j}^{(k)}}}_{\bar{v}_{j}}(y)\right)-\lambda_{k}^{p} v_{k}(x) \bar{v}_{k}(y)\right]+\delta_{m}^{(p)}\left(m_{0}, x, y\right)= \\
& =\sum_{k=1}^{m_{0}}\left[\mu _ { k } ^ { p } \left\{v_{m}(x) \bar{v}_{m}(y)-\frac{v_{m}(x)}{\overline{\operatorname{det} \breve{\mathbf{A}}^{(k)}}} \sum_{j, i=1}^{m-1} \bar{V}_{i m} \overline{\breve{A}}_{i j}^{(k)} \bar{v}_{j}(y)-\frac{\bar{v}_{m}(y)}{\operatorname{det} \breve{\mathbf{A}}^{(k)}} \sum_{j, i=1}^{m-1} V_{i m} \breve{A}_{i j}^{(k)} v_{j}(x)+\right.\right. \\
& \left.\left.+\sum_{j_{1}, j_{2}, i_{1}, i_{2}=1}^{m-1} \frac{V_{i_{1} m} \bar{V}_{i_{2} m} \breve{A}_{i_{1} j_{1}}^{(k)}{\overline{\breve{A}_{i} j_{2}}}_{(k)}}{\operatorname{det} \breve{\mathbf{A}}^{(k)} \overline{\operatorname{det} \breve{\mathbf{A}}^{(k)}}} v_{j_{1}}(x) v_{j_{2}}(y)\right\}-\lambda_{k}^{p} v_{k}(x) \bar{v}_{k}(y)\right]+\delta_{m}^{(p)}\left(m_{0}, x, y\right)=
\end{aligned}
$$




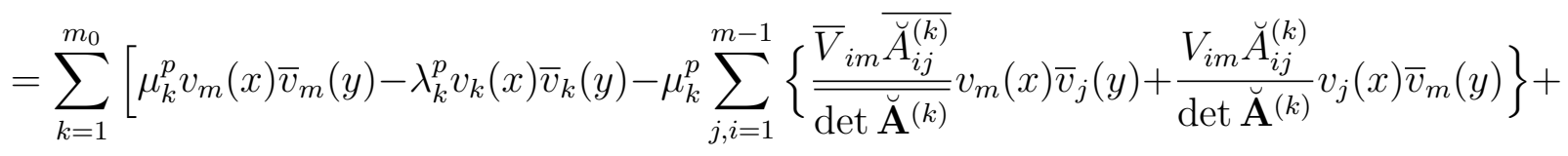

$$
\begin{aligned}
& \left.+\mu_{k}^{p} \sum_{j_{1}, j_{2}, i_{1}, i_{2}=1}^{m-1} \frac{V_{i_{1} m} \bar{V}_{i_{2} m} \breve{A}_{i_{1} j_{1}}^{(k)} \overline{\breve{A}_{i_{2} j_{2}}^{(k)}}}{\operatorname{det} \breve{\mathbf{A}}^{(k)} \overline{\operatorname{det} \breve{\mathbf{A}}^{(k)}}} v_{j_{1}}(x) v_{j_{2}}(y)\right]+\delta_{m}^{(p)}\left(m_{0}, x, y\right)
\end{aligned}
$$

We estimate residues $\left|\delta_{m}^{(p)}\left(m_{0}, x, y\right)\right|$ :

$$
\begin{gathered}
\left|\delta_{m}^{(p)}\left(m_{0}, x, y\right)\right|=\left|\sum_{k=1}^{m_{0}} \mu_{k}^{p}\left[\bar{\varepsilon}_{k}^{(m)} u_{k}^{(m)}(x)+\varepsilon_{k}^{(m)} \bar{u}_{k}^{(m)}(y)+\varepsilon_{k}^{(m)} \bar{\varepsilon}_{k}^{(m)}\right]\right| \leq \\
\leq \sum_{k=1}^{m_{0}}\left|\mu_{k}\right|^{p}\left[\left|C \bar{\varepsilon}_{k}^{(m)} \sum_{j=1}^{m} x_{j}^{(k)}\right|+\left|C \varepsilon_{k}^{(m)} \sum_{j=1}^{m} \bar{x}_{j}^{(k)}\right|+\left|\varepsilon_{k}^{(m)} \bar{\varepsilon}_{k}^{(m)}\right|\right] \leq \\
\leq \sum_{k=1}^{m_{0}}\left|\mu_{k}\right|^{p}\left[2|C| \cdot\left|\varepsilon_{k}^{(m)}\right| \sum_{j=1}^{m}\left|x_{j}^{(k)}\right|+\left|\varepsilon_{k}^{(m)}\right|^{2}\right] .
\end{gathered}
$$

Here $C=\max _{i=1, m}\left|v_{i}(x)\right|$, and $x_{j}^{(k)}$ are calculated by formulas (17).

The theorem is proved.

\section{Computational Experiment}

Let an operator $T=-\Delta$ be defined on the interval $D=[0, l]$. As a perturbing operator $P$ we take the operator of multiplication by function $p(x)$, defined on the interval $D$.

Consider the spectral problem

$$
\begin{gathered}
(T+P) u=\mu u, u \in D_{T} . \\
D_{T}=\left\{u\left|u \in C^{2}(D) \bigcap C(D), \Delta u \in L_{2}[D]: u\right|_{0}=\left.u\right|_{l}=0\right\} .
\end{gathered}
$$

It is well known that eigenvalues $\lambda_{n}$ and eigenfunctions $v_{n}(x)$ of 1-dimensional Laplace operator have the form:

$$
\lambda_{n}=\left(\frac{\pi n}{l}\right)^{2}, v_{n}(x)=\sin \left(\sqrt{\lambda_{n}} x\right), x \in D
$$

Using formulas (7) and (13) the values of the fifth and sixth of the eigenfunctions of the perturbed operator $T+P$ were found. Tables 1 and 2 shows the values of the left and right sides of the equation $(T+P) u_{n}=\mu_{n} u_{n}$.

Table 3 shows the values of the residual $\left\|(T+P) u_{n}-\mu_{n} u_{n}\right\|$ for the first 10 eigenfunctions $u_{n}$ for different perturbing operator $P$. 
Table 1

The values $(T+P) u_{5}$ and $\mu_{5} u_{5}$ for a perturbed Laplace operator calculated for $l=1$ and

$$
p(x)=x^{2}
$$

\begin{tabular}{|c|c|c|c|c|}
\hline$x_{j}$ & $(T+P) u_{5}\left(x_{j}\right)$ & $\mu_{5} u_{5}\left(x_{j}\right)$ & $\left|(T+P) u_{5}\left(x_{j}\right)-\mu_{5} u_{5}\left(x_{j}\right)\right|$ & $\left|\frac{(T+P) u_{5}\left(x_{j}\right)-\mu_{5} u_{5}\left(x_{j}\right)}{\mu_{5} u_{5}\left(x_{j}\right)}\right| \times 100 \%$ \\
\hline 0,142857 & 272,83735198766 & 273,18110548326 & 0,34375 & 0,125834 \\
0,285714 & 340,30702671043 & 340,65126665861 & 0,34424 & 0,101053 \\
0,428571 & 151,51348751144 & 151,60407602055 & 0,09059 & 0,059753 \\
0,571429 & 151,60114526407 & 151,60407602055 & 0,00293 & 0,001933 \\
0,714286 & 340,89792225718 & 340,65126665861 & 0,24666 & 0,072407 \\
0,857143 & 273,62712104909 & 273,18110548325 & 0,44602 & 0,163267 \\
\hline
\end{tabular}

Table 2

The values $(T+P) u_{6}$ and $\mu_{6} u_{6}$ for a perturbed Laplace operator calculated for $l=1$ and

$$
p(x)=\sin \frac{x}{3}+1
$$

\begin{tabular}{|c|c|c|c|c|}
\hline$x_{j}$ & $(T+P) u_{6}\left(x_{j}\right)$ & $\mu_{6} u_{6}\left(x_{j}\right)$ & $\left|(T+P) u_{6}\left(x_{j}\right)-\mu_{6} u_{6}\left(x_{j}\right)\right|$ & $\left|\frac{(T+P) u_{6}\left(x_{j}\right)-\mu_{6} u_{6}\left(x_{j}\right)}{\mu_{6} u_{6}\left(x_{j}\right)}\right| \times 100 \%$ \\
\hline 0,142857 & 218,65994242645 & 218,73206609730 & 0,0721237 & 0,0329735 \\
0,285714 & 394,06411361875 & 394,14156393128 & 0,0774503 & 0,0196504 \\
0,428571 & 491,45509644760 & 491,48649119961 & 0,0313948 & 0,0063877 \\
0,571429 & 491,51983562427 & 491,48649119961 & 0,0333444 & 0,0067844 \\
0,714286 & 394,21974628211 & 394,14156393128 & 0,0781824 & 0,0198361 \\
0,857143 & 218,80367419419 & 218,73206609730 & 0,0716081 & 0,0327378 \\
\hline
\end{tabular}

Table 3

The values of the residual $\left\|(T+P) u_{n}-\mu_{n} u_{n}\right\|$ for a perturbed Laplace operator calculated for $l=1, m=n$

\begin{tabular}{|c|c|c|}
\hline$n$ & $\begin{array}{c}\left\|(T+P) u_{n}-\mu_{n} u_{n}\right\| \\
\text { for }\end{array}$ & $\begin{array}{c}\left\|(T+P) u_{n}-\mu_{n} u_{n}\right\| \\
\text { for }\end{array}$ \\
& $p(x)=\sin \frac{x}{3}+1$ & $p(x)=x^{2}$ \\
\hline 1 & 0,05933175453013449 & 0,18486186946562712 \\
2 & 0,08722167298850077 & 0,26982226399384459 \\
3 & 0,09141711850816346 & 0,28555566913308841 \\
4 & 0,09283781270256698 & 0,29106235945347709 \\
5 & 0,09348757188208574 & 0,29361116877997433 \\
6 & 0,09383850642063260 & 0,29499570545892765 \\
7 & 0,09404942961086482 & 0,29583053561545063 \\
8 & 0,09418605494412680 & 0,29637237064820354 \\
9 & 0,09427960126060587 & 0,29674384907194357 \\
10 & 0,09434645249551450 & 0,29700956347750404 \\
\hline
\end{tabular}

\section{Conclusion}

The paper presents the main theorems, which are used to substantiate the method of regularized traces of finding of the values of eigenfunctions of perturbed self-adjoint operators in the sample nodes. For the first time formulas, which allow to calculate the 
values of sums of functional series of "suspended" corrections of perturbation theory of discrete operators, were obtained. Computational experiments are performed. These experiments allowed to determine the values of the eigenfunctions of the perturbed one-dimensional Laplace operator. The experimental results showed the accuracy and computational efficiency of the developed method.

\section{References}

1. Kadchenko S.I., Kakushkin S.N. The Numerical Methods of Eigenvalues and Eigenfunctions of Perturbed Self-Adjoin Operator Finding. Bulletin of the South Ural State University. Series: Mathematical Modelling, Programming and Computer Software, 2012, no. 27 (286), pp. 45-57. (in Russian)

2. Kadchenko S.I., Kakushkin S.N. Calculation of Values of Eigenfunctions of Discrete Semibounded from Below Operators via the Method of Regularized Traces. Vestnik Samarskogo Gosudarstvennogo Universitetea. Estestvennonauchnaya Seriya, 2012, no. 6 (97), pp. 13-21. (in Russian)

3. Kakushkin S.N. Mathematical Modelling of Finding the Values of Eigenfunctions for the Electrical Oscillations in the Extended Line Problem Using the Method of Regularized Traces. Bulletin of the South Ural State University. Series: Mathematical Modelling, Programming and Computer Software, 2013, vol. 6, no. 3, pp. 125-129. (in Russian)

4. Kadchenko S.I., Kakushkin S.N. Meaning of the First Eigenfunctions of Perturbed Discrete Operators with Simple Spectrum Finding. Bulletin of the South Ural State University. Series: Mathematical Modelling, Programming and Computer Software, 2012, no. 5 (264), pp. 25-32. (in Russian)

5. Sadovnichii V.A., Dubrovskii V.V. Remark on a New Method for Computing of the Eigenvalues and Eigenfunctions of Discrete Operators. Tr. Seminara imeni I.G. Petrovskogo, 1994, vol. 17, pp. 244-248. (in Russian)

6. Sadovnichii V.A. Theory of operators. Moscow, Drofa, 2004. 384 p. (in Russian)

7. Kakushkin S.N. Razvitie chislennykh metodov dlya matematicheskogo modelirovaniya nakhozhdeniya znacheniy sobstvennykh funktsiy vozmushchennykh samosopryazhennykh operatorov [Development of Numerical Methods for Mathematical Modelling of Finding of the Values Eigenfunctions of Perturbed Self-Adjoint Operators. Dissertation of the Candidate of Physical and Mathematical Sciences]. Magnitogorsk, 2013. (in Russian)

8. Kadchenko S.I., Kakushkin S.N. The Algorithm for Finding of Meanings of Eigenfunctions of Perturbed Self-Adjoint Operators via Method Regularized Traces. Bulletin of the South Ural State University. Series: Mathematical Modelling, Programming and Computer Software, 2012, no. 40 (299), pp. 83-88. (in Russian)

9. Kadchenko S.I. Method of Regularized Traces. Bulletin of the South Ural State University. Series: Mathematical Modelling, Programmina and Computer Software, 2009, no. 37 (170), pp. 4-23. (in Russian)

10. Dubrovskii V.V. Teoriya vozmushcheniy $i$ sledy operatorov [Perturbation Theory and Traces of Operators. Dissertation of the Doctor of Physical and Mathematical Sciences]. Moscow, 1992. 
Sergey N. Kakushkin, candidate of physical and mathematical sciences, associate professor, department of Applied Mathematics and Computer Science, Nosov Magnitogorsk State Technical University, Magnitogorsk, Magnitogorsk, Russian Federation, kakushkinsergei@mail.ru.

Sergey I. Kadchenko, doctor of physical and mathematical sciences, professor, department of Applied Mathematics and Computer Science, Nosov Magnitogorsk State Technical University, Magnitogorsk, Magnitogorsk, Russian Federation, kadchenko@masu.ru.

\title{
ВЫЧИСЛЕНИЕ ЗНАЧЕНИЙ СОБСТВЕННЫХ ФУНКЦИЙ ВОЗМУЩЕННЫХ САМОСОПРЯЖЕННЫХ ОПЕРАТОРОВ МЕТОДОМ РЕГУЛЯРИЗОВАННЫХ СЛЕДОВ
}

\author{
С.Н. Какушкин, С.И. Кадченко
}

\begin{abstract}
Авторами статьи был разработан неитерационный численный метод нахождения значений собственных функций возмущенных самосопряженных операторов, названный методом регуляризованных следов. Он позволяет найти значения собственных функций возмущенных дискретных операторов, зная спектральные характеристики невозмущенного оператора и собственные числа возмущенного оператора. В отличии от известных методов, в методе регуляризованных следов значения собственных функций находятся по линейным формулам. Это значительно увеличивает вычислительную эффективность. Сложность применения метода заключается в нахождении сумм функциональных рядов "взвешенных" поправок теории возмущений, которые можно найти лишь численно. В работе приведены формулы, удобные для нахождения "взвешенных" поправок, суммируя которые можно приблизить суммы этих функциональных рядов. Однако, если норма возмущающего оператора велика, то суммирование "взвешенных" поправок бывает не эффективным. В работе получены аналитические формулы нахождения значений сумм функциональных рядов "взвешенных" поправок теории возмущений в узлах дискретизации без непосредственного суммирования его членов. Проведены вычислительные эксперименты по нахождению значений собственных функций возмущенного одномерного оператора Лапласа. Результаты эксперимента показали точность и вычислительную эффективность разработанного метода.

Ключевые слова: метод регуляризованных следов; возмущенные операторы; собственные числа; собственные функции; кратный спектр; "взвешенные" поправки теории возмущений.
\end{abstract}

\section{Литература}

1. Кадченко, С.И. Численные методы нахождения собственных чисел и собственных функций возмущенных самосопряженных операторов / С.И. Кадченко, С.Н. Какушкин // Вестник ЮУрГУ. Серия: Математическое моделирование и программирование. - 2012. - № 27 (286), вып. 13. - С. 45-57. 
2. Кадченко, С.И. Вычисление значений собственных функций дискретных полуограниченных снизу операторов методом регуляризованных следов / С.И. Кадченко, С.Н. Какушкин // Вестник СамГУ. Естественнонаучная серия. - 2012. № 6 (97). - C. 13-21.

3. Какушкин, С.Н. Математическое моделирование спектральной задачи об электрических колебаниях в протяженной линии методом регуляризованных следов / С.Н. Какушкин // Вестник ЮУрГУ. Серия: Математическое моделирование и программирование. - 2013. - Т. 6, № 3. - С. 125-129.

4. Кадченко, С.И. Нахождение значений первых собственных функций возмущенных дискретных операторов с простым спектром / С.И. Кадченко, С.Н. Какушкин // Вестник ЮУрГУ. Серия: Математическое моделирование и программирование. - 2012. - № 5 (264), вып. 11. - С. 25-32.

5. Садовничий, В.А. Замечание об одном новом методе вычислений собственных значений и собственных функций дискретных операторов / В.А. Садовничий, В.В. Дубровский // Тр. семинара им. И.Г. Петровского. - Вып. 17. - М.: МГУ, 1994. - C. 244-248.

6. Садовничий, В.А. Теория операторов / В.А. Садовничий. - М.: Дрофа, 2004. $384 \mathrm{c}$.

7. Какушкин, С.Н. Развитие численных методов для математического моделирования нахождения значений собственных функций возмущенных самосопряженных операторов: дисс. ... канд. физ.-мат. наук/ С.Н. Какушкин. - Магнитогорск, 2013.

8. Кадченко, С.И. Алгоритм нахождения значений собственных функций возмущенных самосопряженных операторов методом регуляризованных следов / С.И. Кадченко, С.Н. Какушкин // Вестник ЮУрГУ. Серия: Математическое моделирование и программирование. - 2012. - № 40 (299). - С. 83-88.

9. Кадченко, С.И. Метод регуляризованных следов / С.И. Кадченко // Вестник ЮУрГУ. Серия: Математическое моделирование и программирование. - 2009. № 37 (170), вып. 4. - С. 4-23.

10. Дубровский, В.В. Теория возмущений и следы операторов: дисс. ... докт. физ.мат. наук / В.В. Дубровский. - Москва, 1992.

Какушкин Сергей Николаевич, кандидат физико-математических наук, дочент, кафедра прикладной математики и информатики, Магнитогорский государственный технический университет им. Г.И. Носова (г. Магнитогорск, Российская Федерачия), kakushkin-sergei@mail.ru.

Кадченко Сергей Иванович, доктор физико-математических наук, профессор, кафедра прикладной математики и информатики, Магнитогорский государственный технический университет им. Г.И. Носова (г. Магнитогорск, Российская Федераuия),kadchenko@masu.ru.

Поступила в редакцию 7 ноября 2015. 